\title{
Therapeutic uses of beta-adrenocepter blocking drugs in the central nervous system in man
}

\author{
Paul Turner \\ Department of Clinical Pharmacology, St. Bartholomew's Hospital, London EC1A 7BE, UK.
}

\begin{abstract}
Although beta-adrenoceptor antagonists were first developed for their potential therapeutic uses in cardiac disease, it was soon recognized during clinical trials that they had effects on the central nervous system, some of them unwanted, but others of possible therapeutic value. This paper reviews some recent developments in this area of beta-adrenoceptor clinical pharmacology, earlier studies having been the subject of other reviews. ${ }^{1-3}$
\end{abstract}

\section{Some possible clinical indications for beta-adrenoceptor blockade}

\section{Anxiety states}

The 1980s have been called 'the age of anxiety', ${ }^{4}$ and not suprisingly, therefore, large numbers of patients have been treated with anxiolytic drugs in recent years. The recognition of the development of physical and psychological dependence on benzodiazepines when taken regularly, even at doses within the therapeutic range, and the occurrence of with drawal syndrome when they are discontinued, has lead to great concern about their use, both among prescribing doctors and the public at large. ${ }^{5}$

It should not be necessary to use drugs in the majority of patients with anxiety, psychological rather than pharmacological therapies being generally the most appropriate first line treatment. ${ }^{6}$ Among the alternative groups of drugs which can be considered in those patients requiring drug treatment, however, are neuroleptics, antidepressants and beta-adrenoceptor blocking drugs.

The efficacy of beta-blockers in the treatment of anxiety has been demonstrated in many controlled clinical trials, both when compared with placebo and with benzodiazepines. ${ }^{6,7}$ Beta-1 receptor blocking drugs, such as atenolol, appear to be as effective as propranolol in patients suffering from generalized anxiety, ${ }^{8}$ but a placebo-controlled trial of the selective

Correspondence: Professor P. Turner, M.D., B.Sc., F.R.C.P. Received: 8 August 1988 beta- 2 blocker ICI 118551 failed to show a therapeutic effect, although the authors were also unable to demonstrate an effect of propranolol in their patients. ${ }^{9}$ It is important to know whether or not the anxiolytic action of beta-blockers is dependent on their selective action at beta- 1 or beta- 2 receptors. In their original paper on propranolol in anxiety, Granville-Grossman and Turner $^{10}$ pointed out that the therapeutic benefit was predominantly upon somatic symptoms, particularly cardiac, which might be expected to be most effectively reduced by beta-1 blockade. However, beta- 2 receptor blockade is more effective than beta- 1 in reducing tremor, ${ }^{11}$ which may also be a prominent symptom in anxiety. Further studies are, therefore, needed to answer this important question.

Some phobic states may benefit from treatment with beta-blockers. Gorman et al., ${ }^{12}$ in an open study, found that atenolol was effective in social phobics who complained of somatic symptoms and a fear of humiliation when confronted with specific social stimuli. They concluded that the mechanism involved was a reduction in the autonomic nervous system response to phobic stimuli. On the other hand, Fagerstrom et al. ${ }^{13}$ compared propranolol, atenolol and placebo in a double-blind trial in similar patients and found that although beta-blockade had the expected effect on heart rate, the subjectively rated anxiety rose consistently during exposure to the phobic stimulus, and there was no general effect of either beta-blocker on subjective anxiety. In general clinical practice, however, Beaumont ${ }^{14}$ claimed that beta-blockers are of value in anticipatory anxiety, in panic disorders, in some phobic patients, and in some generalized anxiety states, and that they should be used in such patients before attempting treatment with benzodiazepine anxiolytics.

\section{Benzodiazepine withdrawal}

Autonomic symptoms and signs are a feature common to symptoms of withdrawal from alcohol, opiates and benzodiazepines. ${ }^{15}$ Seivewright and Tyrer ${ }^{15}$ demonstrated a reduction in severity of benzodiazepine withdrawal symptoms by propranolol, and the

(C) The Fellowship of Postgraduate Medicine, 1989 
preliminary results of a more recent study by Hallstrom et al. ${ }^{5}$ appear to confirm this. Kraus et al. ${ }^{16}$ have shown that atenolol was superior to propranolol in a double-blind trial in management of patients hospitalized with the alcohol withdrawal syndrome.

In these contexts, an important question arises as to whether treatment with beta-blockers can itself produce central nervous dependence and a specific withdrawal state; this is addressed below.

\section{Tremor and other involuntary movements}

The pharmacological treatment of essential tremor has been reviewed recently. ${ }^{17,18}$ Propranolol is considered by many neurologists to be the first choice in management of essential tremor. Intermittent therapy can be useful in patients whose tremor is exacerbated by certain activities and situations. Primidone is an alternative treatment, and in a placebo-controlled double-blind trial was shown to be similar in efficacy to propranolol. ${ }^{19}$ There were, however, frequent complaints of malaise, dizziness and unsteadiness following the first doses of primidone, although thereafter it was well tolerated. Propranolol and primidone can be used together, and their effects may be additive. ${ }^{18}$ There is increasing evidence that beta-2 blockade is responsible for this effect of beta-blockers. In a double-blind cross-over trial in patients with essential tremor, ICI 118551, a selective beta-2 blocker, had a similar effect to propranolol with respect to antitremor efficacy when compared with placebo, but had no effect on heart rate or blood pressure, both of which were reduced by propranolol. ${ }^{20}$

The role of beta-blocking drugs in management of Parkinsonian tremor is more controversial, but Foster et $a .^{21}$ found that nadolol was significantly more effective than placebo in reducing tremor amplitude, but not frequency, in patients with Parkinson's disease who continued their previous dopaminergic and anticholinergic therapy.

The treatment of neuroleptic-induced akathesia is generally unsatisfactory, but some recent studies have suggested that beta-blockade may be effective. In a small single-blind study in 6 patients, Adler et al. ${ }^{22}$ found that propranolol was more effective than lorazepam, and in an open study in 16 patients with severe akathisia, low doses of propranolol produced rapid and complete improvement in 7 , while betaxolol was effective in all 4 patients treated with it. ${ }^{23}$ Adler $e t$ $a l .^{24}$ went on to confirm there observations in a double-blind cross-over trial of propranolol compared with placebo in 12 patients, in which the active treatment significantly improved objective and subjective ratings of akathisia while placebo did not. In a further open study, Adler et al. ${ }^{25}$ found that pindolol was also effective, and suggested that it might be the preferred treatment if a beta-blocker had to be used in a patient with bradycardia. This observation, if confirmed, is of interest as pindolol possesses partial agonist activity and can exacerbate essential and physiological tremor ${ }^{3,26}$ If it is effective in neurolepticinduced akathisia, then the possibility should be considered that the mechanism may not involve beta-blockade but some other pharmacological action. The results of further controlled studies of beta-blocking drugs with different degrees of selectivity, partial agonism and lipid solubility in patients with this distressing condition are awaited with interest.

\section{Migraine}

The evidence for the therapeutic efficacy of betablocking drugs in migraine and the possible pharmacological mechanisms underlying it have recently been reviewed. ${ }^{27-29}$ The value of beta-blockers which are devoid of partial agonist (intrinsic sympathomimetic) activity has been confirmed in a further study $^{30}$ which found that both nadolol and propranolol reduced migraine attack frequency and consumption of acute migraine-relief medication when compared with placebo, but no significant differences were found between the two active drugs. However, the limitations of most published comparative studies of active drugs in migraine because of inadequate numbers of patients have been emphasized ${ }^{29,31}$ and larger more carefully conducted studies are required.

Other studies have compared the prophylactic effects of beta-blockers with non-steroidal antiinflammatory drugs. In a double-blind cross-over trial, ${ }^{32}$ both propranolol and tolfenamic acid significantly decreased the number and duration of migraine attacks, and the consumption of additional drugs, no difference being shown between the active treatments, although the number of 31 patients included was probably too small to show a clinically important, albeit small, difference. Similarly, although another comparison of propranolol and mefenamic acid with placebo showed significant superiority of active over inactive treatments, but no difference between the two drugs, ${ }^{33}$ only 17 of the 29 patients admitted to the study completed the trial, and no serious conclusion can be made on relative efficacy of the two active preparations.

In the absence of definitive understanding of the mechanism of action of beta-blockers in migraine prophylaxis, it has been suggested that psychological effects may be involved. To investigate this further, Ziegler et al. ${ }^{34}$ compared the efficacy of propranolol and amitriptyline in migraine prophylaxis in a doubleblind placebo-controlled cross-over design in 30 patients. Both drugs were superior to placebo, but neither was superior to the other. Furthermore, the effectiveness of neither drug correlated with a decrease 
in anxiety or depression demonstrated by psychological testing with the Speilberger, Zung or Hamilton tests. Nevertheless, on the basis that an enhanced beneficial therapeutic effect might accrue from combination of an antidepressive drug and a beta-blocker in patients with headache due to migraine and tension together ('combination headache'), Pfaffenrath et al..$^{35}$ gave a combination of amitriptyline and a beta-blocker (propranolol or metoprolol) to 61 patients with combination headache in an open uncontrolled trial, and demonstrated a marked reduction in headache frequency. This cannot be considered more than preliminary evidence, however, which requires confirmation in a placebo-controlled trial in adequate numbers of patients.

Although beta-blockers are generally well tolerated in patients with migraine ${ }^{36}$ vasospastic and occlusive complications have been described. ${ }^{28}$ More recently, Bardwell and Trott ${ }^{37}$ have reviewed the literature on stroke in migraine, including the mechanism of action of beta-blockers, and have questioned the appropriateness of using these agents indiscriminately for migraine prophylaxis, particularly in patients where migraine attacks have been associated with or preceded by conspicuous sensory or motor deficits.

A relationship appears to exist between migraine and somnambulism, and the possibility has been raised $^{38}$ that propranolol may be capable of triggering episodes of somnambulism in patients already troubled by it or with a history of this disorder in childhood.

It is evident, therefore, that the definitive place of beta-blocking drugs in the prophylaxis of migraine, and the recognition of those patients most likely to benefit from them, still awaits final elucidation.

\section{Schizophrenia}

The therapeutic efficacy of propranolol in acute schizophrenia is still uncertain, and little significant advance has been made in the subject since we last reviewed it. ${ }^{2}$ More evidence has accumulated that the addition of propranolol to treatment with phenothiazines such as thioridazine leads to marked increases in plasma levels of the latter, ${ }^{39}$ but not to changes in haloperidol levels. ${ }^{40}$ The latter observation raises the possibility that the therapeutic action of propranolol may not be entirely due to its pharmacokinetic interaction, and this is supported by a further double-blind placebo-controlled study ${ }^{41}$ in patients treated initially with haloperidol which showed that the dextro-isomer of propranolol had a small but significant therapeutic effect in preventing deterioration in a group of acute schizophrenics when the haloperidol had been withdrawn. The pharmacological basis of this antipsychotic action of D-propranolol is unknown.

\section{Aggressive syndromes}

Several open studies have suggested that betablocking drugs are of value in controlling aggressive behaviour associated with chronic schizophrenia, ${ }^{42}$ organic brain disease, ${ }^{43-45}$ autism, ${ }^{46}$ as well as in patients with temper outbursts but no evidence of other central nervous disease. ${ }^{47}$ This is a difficult group of syndromes to subject to double-blind assessment, but Greendyke and $\mathrm{Kanter}^{48}$ carried out a doubleblind placebo-controlled cross-over study with pindolol in 11 patients with impulsive, explosive behaviour due to brain disease. Pindolol treatment was associated with significant therapeutic benefit without sedation or other use-limiting effects.

It is of interest that a paradoxical violent episode has been described as part of a psychotic reaction to propranolol in therapeutic doses. ${ }^{49}$ Similar paradoxical effects have been described with the usually anti-aggressive benzodiazepine drugs. ${ }^{50}$

\section{Sleep disturbances}

The adverse effect of lipid soluble beta-blockers on sleep ${ }^{2}$ and the influence of propranolol on somnambulism $^{38}$ have been discussed elsewhere in this review. It is of interest, therefore, that propranolol has been claimed to have beneficial short-term effects in narcoleptic patients, although in the long-term the benefit disappeared. ${ }^{51}$ Despite its anxiolytic properties (see above), in a double-blind placebo-controlled crossover trial propranolol did not show any hypnotic properties, and even increased the insomnia in a sample of patients previously treated chronically with conventional hypnotic drugs, mainly benzodiazepines. $^{52}$

The possibility that nightmares and hallucinations associated with treatment with beta-blocking drugs might be associated with depression in pineal melatonin secretion has been investigated by Brismar et $a l^{53}$ They found that nightly urinary melatonin excretion was lower in all six patients with nocturnal central nervous system (CNS) symptoms than in six control patients with similar diagnoses and treatments but without such nocturnal CNS symptoms. It is possible, however, that melatonin secretion serves only as a marker for central noradrenergic activity (see below), and the changes seen in this study are unlikely to contribute significantly to understanding the nature of the sleep disturbance apart from focussing attention on the central noradrenergic system.

\section{Is there a beta-blocker withdrawal syndrome involving the central nervous system?}

The abrupt withdrawal of beta-blocking drugs, particularly those without partial agonist activity, can rarely 
be associated with a cardiovascular withdrawal syndrome. ${ }^{3}$ Can such a syndrome occur in the central nervous system? Anecdotal reports suggest that this might be so. For example, Patterson ${ }^{54}$ described a 46 year old male patient who developed a psychotic reaction on withdrawal of a long-acting propranolol preparation prescribed for hypertension. This reaction remitted on recommencing propranolol treatment.

The increasing use of beta-blockers, particularly propranolol for neuropsychiatric indications such as those discussed above, makes it essential to determine whether or not a clinically important central nervous withdrawal syndrome occurs following their use, and if so, its incidence. In a recent study, Al-Qassab et al. ${ }^{55}$ compared the effects of abrupt withdrawal of propranolol with those of continuing treatment on tremor, melatonin excretion and rating scales of sleep, mood and vigilance in normal subjects. The only observation which suggested any form of withdrawal syndrome was a complaint of insomnia in some subjects during the first two weeks of withdrawal compared with none in the treatment-continued group, but this did not reach statistical significance. While the results of this study are encouraging, their implications are limited. Studies of the cardiovascular withdrawal syndrome involve studying the effects of beta-receptor agonists on peripheral measurements such as heart rate and tremor. No such agonist models of central betareceptor function have yet been developed, and so strictly comparable studies have not yet been carried out. Until they are, the question of whether or not a central nervous beta-adrenoceptor withdrawal syndrome can occur must remain in doubt.

\section{Unwanted central effects of beta-blocking drugs}

Unwanted effects of beta-blocking drugs on the human central nervous system have been described

\section{References}

1. Patel, L. \& Turner, P. Central action of betaadrenoceptor blocking drugs in man. Med Res Rev 1981, 1: $387-410$.

2. Turner, P. Beta adrenoceptor blocking drugs and the central nervous system in man. In: Turner, P \& Shand, D.G. (eds) Recent Advances in Clinical Pharmacology, vol. 3. Churchill Livingstone, Edinburgh, 1983, pp. 223-234.

3. Cruickshank, J.M. \& Prichard, B.N.C. Beta Blockers in Clinical Practice. Churchill Livingstone, Edinburgh, 1987.

4. Paykel, E.S. Introduction. Postgrad Med J 1988, 64 (Suppl 2): 1. since they were first introduced into clinical medicine, ${ }^{2}$ and reports and studies on them continue to appear in the literature. Sophisticated methodology for detecting the impairing effects of drugs on central nervous function in normal volunteers has permitted the recognition of such effects following modest doses of a variety of beta-blockers, including the hydrophilic drug atenolol. ${ }^{56}$ However, clinical studies in hypertensive patients suggest that the clinical importance of such central effects is generally not significant ${ }^{57-59}$ although occasional cases of depression may occur, sometimes even following topical ocular administration for treatment of glaucoma. ${ }^{60}$ It is important, therefore, to be aware of these important, albeit uncommon, unwanted effects of beta-blocker therapy.

\section{Central receptor activity of beta-receptor blocking drugs}

Preliminary evidence that beta-adrenoceptor blocking drugs might interact with central 5-hydroxytryptamine (5HT) as well as noradrenergic systems has been reviewed elsewhere. ${ }^{2}$ Recent studies have attempted to identify the 5HT receptor subtypes involved, and it appears from animal brain studies that $L$ propranolol and racemic cyanopindolol act as mixed agonist-antagonists at $5 \mathrm{HT}_{1 \mathrm{~B}}$ autoreceptors. ${ }^{61}$ Another study ${ }^{62}$ suggests that L-propranolol also interacts with $5 \mathrm{HT}_{1 \mathrm{~A}}$ receptor, distinct from the $5 \mathrm{HT}_{1 \mathrm{~B}}$ receptor which may be present in intracranial blood vessels. It is evident that the pharmacological mechanisms underlying the central nervous effects of beta-blocking drugs reviewed above have not yet been elucidated, but almost certainly involve factors additional to beta-receptor blockade.

5. Hallstrom, C., Crouch, G., Robson, M. \& Shire, P. The treatment of tranquilizer dependence by propranolol. Postgrad Med J 1988, 64 (Suppl 2): 40-44.

6. Peet, M. The treatment of anxiety with beta-blocking drugs. Postgrad Med J 1988, 64 (Suppl 2): 45-49.

7. Meibach, R.C., Mullane, J.F. \& Binstok, G. A placebocontrolled multicenter trial of propranolol and chlordiazepoxide in the treatment of anxiety. Curr Ther Res 1987, 41: 65-76.

8. Peet, M. \& Ali, S. Propranolol and atenolol in the treatment of anxiety. Int Clin Psychopharmacol 1986, 1: 314-319. 
9. King, D.J., Devaney, N.M. \& Gilbert, J.K. A double blind placebo-controlled trial of a selective $B_{2}$ adrenoceptor antagonist (ICI 118551) in chronic anxiety. Int Clin Psychcopharmacol 1987, 2: 191-200.

10. Granville-Grossman, K. \& Turner, P. The effect of propranolol on anxiety. Lancet 1966, i: 788-790.

11. Jefferson, D., Wharrad, H.J., Birmingham, A.T. \& Patrick J.M. The comparative effects of ICI 118551 and propranolol on essential tremor. Br J Clin Pharmacol 1987, 24: 729-734.

12. Gorman, J.M., Liebowitz, M.R., Fyer, A.J., Campeas, R. \& Klein, D.F. Treatment of social phobia with atenolol. J Clin Psychopharmocol 1985, 5: 298-301.

13. Fagerstrom, K.O., Hugdahl, K. \& Lundstrom, N. Effect of beta-receptor blockade on anxiety with reference to the three-systems model of phobic behaviour. Neuropsychobiol 1985, 13: 187-193.

14. Beaumont, G. Panel discussion. Postgrad Med J 1988, 64 (Suppl 2): 51.

15. Seivewright, N.S. \& Tyrer, P.J. Use of beta-blocking drugs in withdrawal states. Postgrad Med J 1984, 60 (Suppl 2): 47-50.

16. Kraus, M.L., Gottlieb, L.D., Horwitz, R.I. \& Anscher, $M$. Randomised clinical trial of atenolol in patients with alcohol withdrawal. $N$ Engl J Med 1985, 313: 905-909.

17. Findley, L.J. The pharmacological management of essential tremor. Clin Neuropharmacol 1986; 9 (Suppl 2): S61 -75 .

18. Findley, L.J. \& Koller, W.C. Essential tremor; a review. Neurology 1987, 37: 1194-1197.

19. Gorman, W.P., Cooper, R., Pocock, P. \& Campbell, M.J. A comparison of primidone, propranolol and placebo in essential tremor, using quantitative analysis. $J$ Neurol Neurosurg Psychiatry 1986, 49: 64-68.

20. Teravainen, H., Huttunen, J. \& Larsen, T.A. Selective adrenergic beta-2-receptor blocking drug ICI 118551 is effective in essential tremor. Acta Neurol Scand 1986, 74: 34-37.

21. Foster, N.L., Newman, R.P., Le Witt, P.A., Gillespie, M.M., Larson, T.A. \& Chase, T.N. Perepheral betaadrenergic blockade treatment of Parkinsonian tremor. Ann Neurol 1984, 16: 505-508.

22. Adler, L., Angrist, B., Peselow, E., Corwin, J. \& Rotrosen, J. Efficacy of propranolol in neurolepticinduced akathisia. J Clin Psychopharmacol 1985, 5: 164-166.

23. Dupuis, B., Catteau, J., Dumon, J.-P., Hibert, C. \& Petit, H. Comparison of propranolol, sotalol and betaxolol in the treatment of neuroleptic-induced akathisia. $A m ~ J$ Psychiatry 1987, 144: 802-805.

24. Adler, L., Angrist, B., Peselow, E., Corwin, J. Maslansky, R. \& Rotrosen, J. A controlled assessment of propranolol in the treatment of neuroleptic-induced akathisia. Br J Psychiatry 1986, 149: 42-45.

25. Adler, La., Reiter, S., Angrist, B. \& Rotrosen, J. Pindolol and propranolol in neuroleptic-induced akathisia. $\mathrm{Am} \mathrm{J}$ Psychiatry 1987, 144: 1241-1242.

26. Hod, H., Har-Zahav, J., Kaplinsky, N. \& Frankl, O. Pindolol-induced tremor. Postgrad Med J 1980, 56: $346-347$.

27. Weerasuriya, K., Patel, L. \& Turner, P. Betaadrenoceptor blockade and migraine. Cephalalgia 1982 , 2: $33-45$.
28. Turner, P. Beta-blocking drugs in migraine. Postgrad Med J 1984, 60 (Suppl 2): 51-55.

29. Turner, P. Beta-adrenoceptor blocking drugs in the prophylaxis of migraine - a critical review. In: Blau, J.N. (ed.), Migraine, Chapman and Hall, London, 1987, pp. 533-542.

30. Olerud, B., Gustavsson, C.-L. \& Furberg, B. Nadolol and propranolol in migraine management. Headache 1986, 26: 490-493.

31. Tfelt-Hansen, P. Efficacy of beta-blockers in migraine. Cephalalgia 1986, 6 (Suppl 5): 15-24.

32. Mikkelsen, B., Pedersen, K.K. \& Christiansen, L.V. Prophylactic treatment of migraine with tolfenamic acid propranolol and placebo. Acta Neurol Scand 1986, 73: 423-427.

33. Johnson, R.H., Hornabrook, R.W. \& Lambie, D.G. Comparison of mefenamic acid and propranolol with placebo in migraine. Acta Neurol Scand 1986, 73: 490-492.

34. Ziegler, D.K., Hurwitz, A., Hassanein, R.S., Kodanaz, H.A., Preskorn, S.H. \& Mason, J. Migraine prophylaxis: a comparison of propranolol and amitriptyline. Arch Neurol 1987, 44: 486-489.

35. Pfaffenrath, V., Kellhammer, U. \& Pollmann, W. Combination headache: practical experience with a combination of a beta-blocker and an antidepressive. Cephalalgia 1986, 6 (Suppl 5): 25-32.

36. Diamond, S., Solomon, G.D., Freitag, F.G. \& Mehta, N.D. Long-acting propranolol in the prophylaxis of migraine. Headache 1987, 27: 70-72.

37. Bardwell, A. \& Trott, J.A. Stroke in migraine as a consequence of propranolol. Headache 1987, 27: 381-383.

38. Pradalier, A., Giroud, M. \& Dry, J. Somnambulism, migraine and propranolol. Headache 1987, 27: 143-145.

39. Silver, J.M., Yudofsky, S.C., Kogan, M. \& Katz, B.L. Elevation of thioridazine plasma levels by propranolol. Am J Psychiatry 1986, 143: 1290-1292.

40. Greendyke, R.M. \& Kanter, D.R. Plasma propranolol levels and their effect on plasma thioridazine and haloperidol concentrations. J Clin Psychopharmacol 1987, 7: $178-182$.

41. Manchanda, R. \& Hirsch, S.R. Does propranolol have an antipsychotic effect? A placebo-controlled study in acute schizophrenia. Br J Psychiatry 1986, 148: 701-707.

42. Sorgi, P.J., Ratey, J.J. \& Polakoff, S. Beta-adrenergic blockers for the control of aggressive behaviours in patients with chronic schizophrenia. Am J Psychiatry 1986, 143: 775-776.

43. Greendyke, R.M., Schuster, D.G. \& Wooton, J.A. Propranolol in the treatment of assaultive patients with organic brain disease. J Clin Psychopharmacol 1984, 4: $282-285$.

44. Jenike, M.A. Propranolol as treatment for aggressive behaviour in elderly brain-damaged patients. Clin Gerontologist 1985, 3: 36-39.

45. Mattes, J.A. Metoprolol for intermittent explosive disorder. Am J Psychiatry 1985, 142: 1108-1109.

46. Ratey, J.J., Mikkelsen, E., Sorgi, P. et al. Autism: the treatment of aggressive behaviours. J Clin Psychopharmacol 1987, 7: 35-41. 
47. Mattes, J.A., Propranolol for adults with temper outbursts and residual attention deficit disorder. $J$ Clin Psychopharmacol 1986, 6: 299-302.

48. Greendyke, R.M. \& Kanter, D.R. Therapeutic effects of pindolol on behavioural disturbances associated with organic brain disease: a double-blind study. J Clin Psychiatry 1986, 47: 423-426.

49. Cunnane, J.G. \& Blackwood, G.W. Psychosis with propranolol: still not recognised? Postgrad Med J 1987, 63: 57-58.

50. Sheard, M.H. Clinical pharmacology of aggressive behaviour. Clin Neuropharmacol 1984, 7: 173-183.

51. Meier-Ewert, K., Matsubayashi, K. \& Benter, L. Propranolol: long term treatment in narcolepsy-cataplexy. Sleep 1985, 8: 95-104.

52. Danjou, P., Puech, A., Warot, D., Benoit, J.-F. Lack of sleep-inducing properties of propranolol $(80 \mathrm{mg})$ in chronic insomniacs previously treated by common hypnotic medications. Clin Psychopharmacol 1987, 2: 134- 140 .

53. Brismar, K., Mogensen, L. \& Wetterberg, L. Depressed melatonin secretion in patients with nightmares due to beta-adrenoceptor blocking drugs. Acta Med Scand 1987, 221: 155-158.

54. Patterson, J.F. Psychosis following discontinuation of a long-acting propranolol preparation. J Clin Psychopharmacol 1985, 5: 125-126.

55. Al-Qassab, H., Cleeves, L.A., Francis, P.L. et al. Is there a central nervous withdrawal syndrome associated with discontinuing long term treatment with propranolol? Hum Toxicol 1988, 7: 249-254.
56. Currie, D., Lewis, R. \& McDevitt, D.G. Central effects of the beta adrenoceptor antagonists propranolol and atenolol. Br J Clin Pharmacol 1988, 15: 124P.

57. Madden, D.J., Blumenthal, J.A., Ekelund, L.-G., Krantz, D.S., Light, K.C. \& McKee, D.C. Memory performance by mild hypertensives following betaadrenergic blockade. Psychopharmocology 1986, 89: 20-24.

58. Gengo, F.M., Fagan, S.C., Padova, A., Miller, J.K. \& Kirkel, P.R. The effect of beta-blockers on mental performance in older hypertensive patients. Arch Int Med 1988, 148: 779-784.

59. Frohlich, E.D. Beta-blockers and mental performance. Arch Int Med 1988, 148: 777-778.

60. Shore, J.H., Fraunfelder, F.T. \& Meyer, S.M. Psychiatric side effects from topical ocular timolol, a beta adrenergic blocker. J Clin Psychopharmacol 1987, 7: 264-267.

61. Maura, G., Ulivi, M. \& Raiteri, M. L-Propranolol and racemic cyanopindolol are mixed agonists - antagonists at serotonin autoreceptors in the hippocampus of the rat brain. Neuropharmacology 1987, 26: 713-717.

62. Hiner, B.C., Roth, H.L. \& Peroutka, S.J. Antimigraine drug interactions with 5-hydroxytryptamine $1 \mathrm{~A}$ receptors. Ann Neurol 1986, 19: 511-513. 